\title{
Study on Temperature Field of Buried Heat Exchanger in a Residential District
}

\author{
WANG Kai ${ }^{1}$, MIN Jie ${ }^{1}$, SHENG Xuelei ${ }^{1}$, WANG Haitao ${ }^{1 *}$ \\ ${ }^{1}$ School of Environment and Energy Engineering, Anhui jianzhu University, Anhui Hefei,230601, China
}

\begin{abstract}
The long-term stable operation of soil source heat pump system depends on the recovery characteristics of soil temperature field. Using DEST-h model of Hefei a high-rise residential buildings and FLUENT software to simulate software of soil source heat pump are analyzed through the summer and autumn season recovery after the change of soil temperature field around the buried pipe. It is pointed out that the intermittent operation of the compensation tower soil-coupled heat pump is beneficial to promote the recovery of soil temperature field. It has certain engineering application value for the improvement of soil source heat pump performance in hot summer and cold winter area.
\end{abstract}

\section{Introduction}

The soil source heat pump system is an energy efficient and environmentally friendly energy utilization device that utilizes shallow geothermal energy (Figure 1).

Studies have shown that even if the underground thermostatic belt in the area only rises by $0.5^{\circ} \mathrm{C}$ per year, the soil-source heat pump system will not work effectively after 10 years ${ }^{[1-2]}$. Therefore, ensuring the underground heat balance is the key to the good operation of the soil source heat pump system ${ }^{[3-4]}$. Some scholars have indicated that using proper joint operation of the cooling tower and the buried tube heat exchanger, the size of the buried heat exchanger and the construction cost can be reduced, the soil source heat pump also can be intermittently operated, which is beneficial to the underground. The recovery of soil temperature around the buried heat exchanger improves the operating efficiency of the soil source heat pump ${ }^{[5-10]}$.

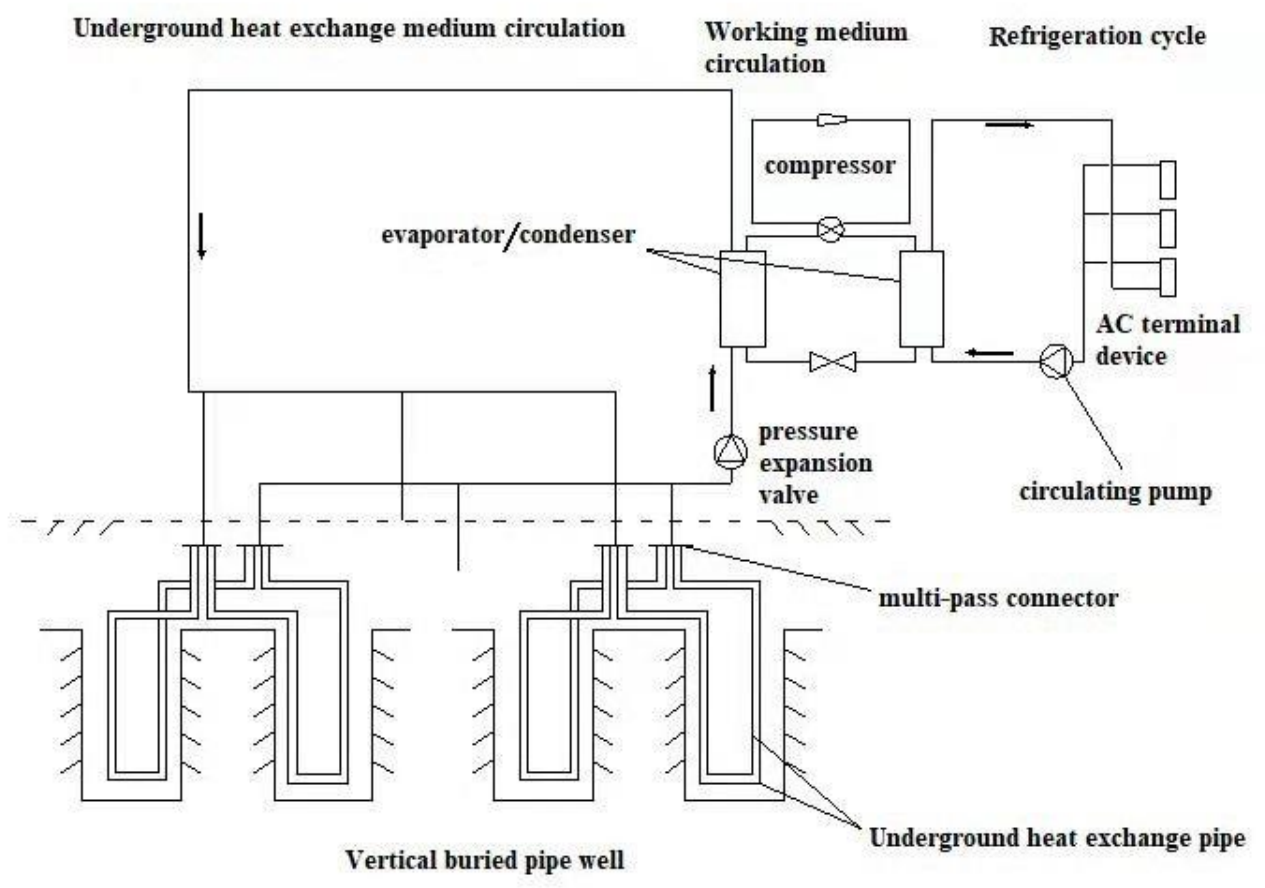

Fig.1 Schematic diagram of the working principle of the soil source heat pump

\footnotetext{
* Corresponding author: wht@ahjzu.edu.cn
} 


\section{Engineering application examples}

Taking a high-rise residential area in Hefei as an example, the total construction area of the residential area is 65,850 $\mathrm{m}^{2}$, and the first floor is a equipment room, and the rest is a garage. The district uses the cooling tower compensation type coupled soil source heat pump system as the cold and heat source of the air conditioning system. After calculation, the total cooling load is $4990 \mathrm{~kW}$ and the total heat load is $2530 \mathrm{~kW}$. Air conditioning load is specifically designed to mean that the soil source heat pump bears all the winter air conditioning heat load, and bears part of the summer air conditioning cooling load. The rest of the cooling load and the peak cooling load are borne by the cooling tower.

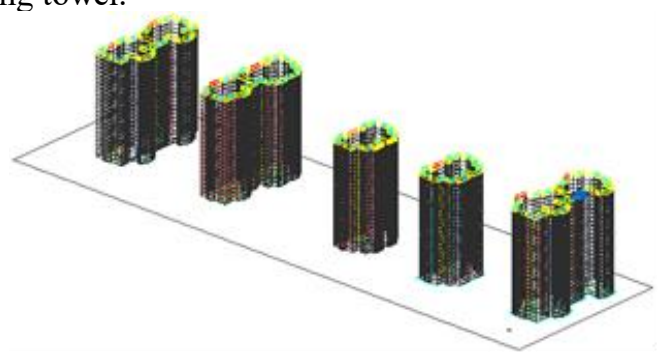

Fig. 2 DEST-H three-dimensional model of high-rise residential buildings

\subsection{Geothermal property parameter test}

\subsubsection{Initial temperature}

The tester 60 s automatically collects and records the data once, and continuously collects it for 2 hours. After the flow rate and pressure are stabilized, the data is collected. The initial temperature of the test hole 1 and the test hole 4 is measured as shown in Fig 3 and Fig4.

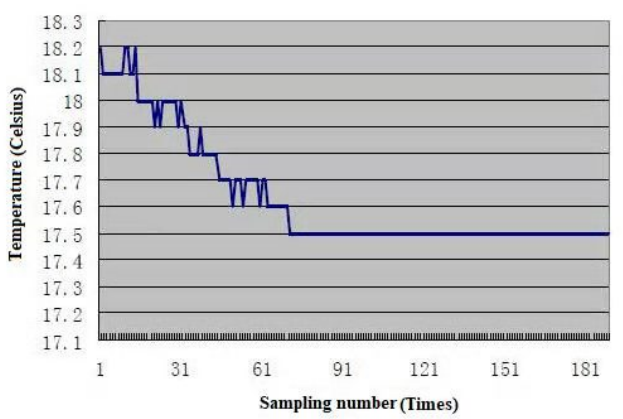

Fig. 3 test hole 1 initial temperature

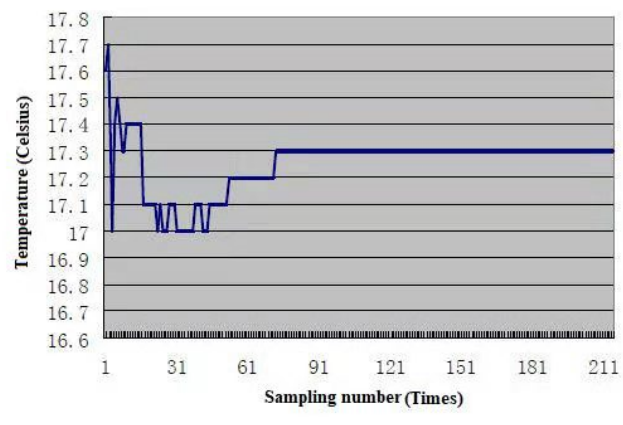

Fig. 4 test hole 4 initial temperature

\subsubsection{Exothermic conditions}

After obtaining the initial temperature of the test hole, the heating switch is turned on for constant heating flow test, and the test data is automatically collected and recorded once in 60 seconds, continuously tested for more than 24 hours, the circulating water flow rate is $0.6 \mathrm{~m} / \mathrm{s}$, and the test hole 1 and the test hole 4 are measured for water supply and return. The water temperature curve is shown in Figures 5 and 6.

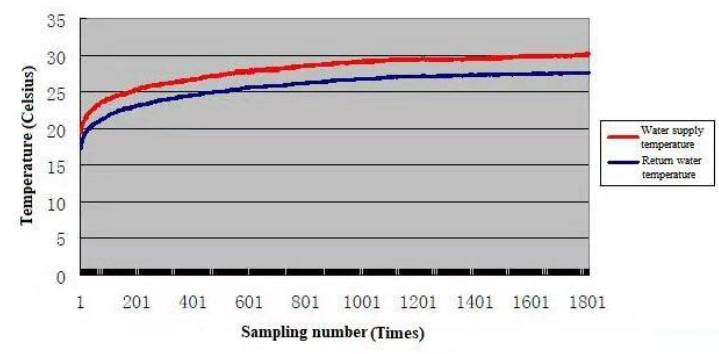

Fig. 5 Test hole 1 supply and return water temperature curve

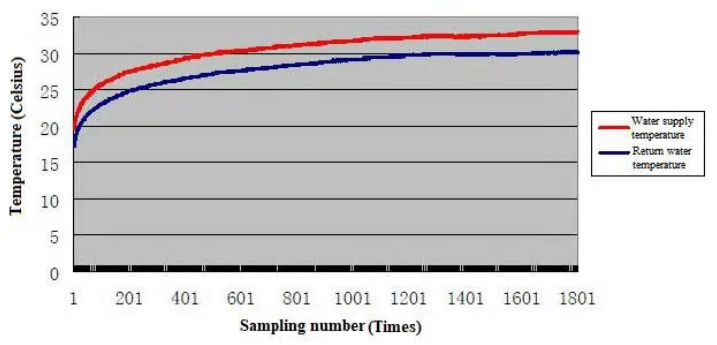

Fig. 6 Test hole 4 supply and return water temperature curve

\subsection{Cooling tower}

In this project design, all the required cooling load is $4990 \mathrm{kw}$. Take the most commonly used cop value of 6.0, the unit with the inlet and outlet water temperature difference of $5{ }^{\circ} \mathrm{C}$ as an example. After calculation, the peak cooling load should be met, the cooling water volume should not be lower than $780 \mathrm{CMH}$, and the loss of water such as evaporation loss, wind blow loss, and sewage loss should be considered. The cooling tower was determined with a circulating water volume of $850 \mathrm{CMH}$. 


\section{Numerical simulation analysis of temperature field of buried pipe}

\section{1 buried pipe area and structure}

According to the actual operation of the system and the arrangement of buried pipe heat exchanger in drilling area, the typical area is simulated first and then analyzed. Considering the geometric symmetry of the buried area of the heat exchanger pipe and the uniform distribution of the heat exchanger area, it is reasonable to choose $25 \%$ of the typical area as the simulated calculation area.

\subsection{Simulation hypothesis}

The heat transfer process between the buried pipe heat exchanger and the surrounding soil can be understood as the process of heat transfer from one medium to the distant soil through another multi-layer medium, and the soil around the buried pipe and backfill is a kind of complex material with mixed solid-liquid, uneven density and porous. Therefore, the heat transfer of materials around the buried tube heat exchanger can be divided into two types of heat transfer: heat conduction and heat convective heat transfer, which is a typical heat and mass transfer process, which is accompanied by convective heat transfer caused by moisture transfer. In terms of heat transfer, in order to simplify the problem, the heat transfer and heat transfer process of simple heat conduction process and heat and mass transfer process are highly similar to those of heat and mass transfer process.

\section{3 initial and boundary conditions}

The average temperature of soil temperature field was $18.5^{\circ} \mathrm{C}$ after the ground source heat pump was operated for a period of time. The wall has no slip boundary, and the heat flow is loaded.

\subsection{Analysis of soil temperature field}

\subsubsection{Field temperature change analysis}

Under the condition of ensuring the normal load, the longterm stable operation of the buried pipe heat exchanger in the ground source heat pump system is largely determined by whether the soil around the heat exchanger can basically maintain the thermal balance during the operation cycle. Therefore, it is necessary to observe the change of soil temperature by simulation calculation, in order to test whether the design load of underground pipe heat exchanger has basic matching with the actual situation.

It can be seen that the temperature of the soil rises to $24.2^{\circ} \mathrm{C}$ after the operation of the refrigeration unit, and the natural temperature of the soil drops to $21.1^{\circ} \mathrm{C}$ and the temperature drops to $3.2^{\circ} \mathrm{C}$ after the operation of the refrigeration unit.

\subsubsection{Analysis of point temperature variation.}

(1) Soil temperature monitoring points

The monitoring points are set up in the typical area of the group wells to study and analyze the local temperature variation of the heat exchanger. In this design, if the coordinate of the center point of the well group is taken as the origin, the monitoring point is set at the central position of the layout of the well group.

(2) Monitoring point temperature change

It can be seen that the temperature change curve is October as the dividing point, the left side increases monotonously, the right side monotonously decreases, it is easy to conclude that the typical position temperature of well group increases gradually in refrigerating season, decreases gradually in autumn, and decreases about $1{ }^{\circ} \mathrm{C}$ at the end of the year. The system stops running in autumn, so that the soil temperature can be restored in a certain time, so that the heat balance can be basically maintained during the working cycle of the ground source heat pump system.

\section{Conclusion}

With the periodic operation of the whole ground source heat pump system, the soil around the ground pipe heat exchanger goes through the periodic process of rising and falling temperature. The temperature near the wellbore fluctuates up and down with the change of heat transfer load, and the temperature far from the wellbore shows the law of gentle rise or decrease. In the hot summer and cold winter area, because the cooling season is generally longer than the heating season, after the heat release of the unit in summer and the heat dissipation in autumn, the soil temperature around the buried pipe is still slightly higher than that in the initial state, so there is a certain amount of ${ }^{\circ} \mathrm{C}$ heat accumulation in the soil, and the heat balance is lost. Therefore, whether the system can operate reliably for a long time mainly depends on whether the load of refrigeration season and heating season is balanced. The soil coupled heat pump system with cooling tower compensation in hot summer and cold winter area has certain reference value for engineering popularization and application for improving the performance of ground source heat pump.

\section{Acknowledgment}

This work is supported by the Key Research and Development Special Project of Anhui province of China (201904a07020072).

\section{References}

1. B. Hu, Y. Li, B. Mu. Extremum seeking control for efficient operation of hybrid ground source heat pump system[J]. Renewable Energy.86(2016),332-346.

2. W. Cui, S. Zhou, X. Liu. Optimization of design and operation parameters for hybrid ground-source heat pump assisted with cooling tower. Energy and Buildings .99(2015),253-262. 
3. R. Fan, Y. Gao, L. Hua, et al. Thermal performance and operation strategy optimization for a practical hybrid ground-source heat-pump system[J]. Energy and Buildings .78(2014),238-247.

4. L. Schibuola, C. Tambani, A. Zarrella, at al. Ground source heat pump performance in case of high humidity soil and yearly balanced heat transfer[J].

Energy Conversation and Management .76(2013),956-970.

5. GUO Erbao. Numerical Simulation and Experimental Research on the Temperature Field around Groundloop Heat Exchanger[J]. FLUID MACHINERY.2016, 44(11):61-66

6. GUO Erbao, ZHANG Wentao, TANG Weiwei. Performance research on the large scale application of ground coupled heat pump system in Hefei[J]. CRYOGENICS \& SUPERCONDUCTIVITY.41(1): 7681

7. Gao Xiuzhi,Wang Fenghao,Ji Kunchi,Wang Zhihua,Liu Jun,Cai Wanlong.Development status and prospects of heat pump heating technology[J]. Refrigeration and Air-Conditioning.2019, 19(5): 7178

8. Wang Lei, Wang Jinbo. A Study on Energy Efficiency Performance of two Different Hybrid Ground Source Heat Pump Systems[J]. Refrigeration and AirConditioning.2018, 32(6): 631-635

9. CHEN ZhengShun, YU YueJin. Experimental Study of HGSHP Operation in Summer[J]. FLUID MACHINERY.2015, 06: 66-68+55

10. YANG Yan, ZHAI Xiao-Qiang, YU Xin, WANG RuZhu. The Experimental Study on Heat Balance and Soil Temperature Distribution of Ground Source Heat Pump of Air-Conditioning System[J]. Journal of Engineering Thermophysics.2011, 32(11):1819-1822 